\title{
A Psycholinguistic Theory of Loanword Adaptations
}

\author{
SHARON PEPERKAMP \\ Laboratoire de Sciences Cognitives et Psycholinguistique, EHESS-ENS-CNRS, \\ and Université de Paris 8
}

\section{Introduction}

Phonologists have long held an interest in loanword adaptations, that is in the transformations that apply to words when they are borrowed into a foreign language. Starting with Hyman (1970), it is generally assumed in generative grammar that the input to loanword adaptations is constituted by the surface form of the source language, and that the adaptations are computed by the phonological grammar of the borrowing language. In rule-based phonology, loanword adaptations present one oddity: given that foreign words often contain illegal structures that are absent from underlying forms in the native phonology, novel rules should be added to the grammar to deal with their adaptations. This undesirable feature is absent from constraint-based phonology, in which the transformations in loanwords are driven by constraints that are already part of the grammar. The rise of constraint-based theories has thus given a particularly strong impetus to the study of loanword adaptations, and a steady flow of articles has appeared that analyze loanword adaptations within such output-oriented frameworks (see, among others, Yip 1993; Paradis \& LaCharité 1997; Ulrich 1997; Broselow 2000, in press; Rose 1999; Golston \& Yang 2001; Jacobs \& Gussenhoven 2000; Kenstowicz 2001).

Within constraint-based frameworks, it has been argued that loanword adaptations are in conformity with the native phonology (Yip 1993; Paradis 1995; Broselow 2000; Jacobs \& Gussenhoven 2000), and even that they provide insight into it, revealing the relative ranking of faithfulness constraints that would otherwise remain 'hidden' (see, for instance, Jacobs \& Gussenhoven (2000)). Against the current view, I argue that loanword adaptations are not computed by the phonological grammar of the borrowing language. First, I show that not all loanword adaptations are in accordance with the native phonology. Second, I argue that separating these problematic cases from the remaining loanword adaptations and treating them differently, by making appeal to phonetic and/or perceptual arguments, yields an ad hoc distinction between phonological and nonphonological adaptations. Finally, I propose that a principled solution lies with the hypothesis that all loanword adaptations are phonetically minimal transformations 
that apply during speech perception. This hypothesis is motivated independently by psycholinguistic data concerning the perception of non-native sound structures.

Before going into the arguments, it is useful to distinguish two types of loanwords. First, integrated loanwords, i.e. words that have entered the lexicon of the borrowing language, have been studied most often. Monolingual speakers who use these loanwords never hear their source forms, and there is thus no reason to postulate an underlying form that differs from the surface form in their grammar. In other words, a phonological analysis of the modifications these words have undergone when entering the borrowing language has no direct psychological reality. Rather, it receives a diachronic interpretation, in that it accounts for the adaptations applied by those speakers who have originally introduced the loans. The second type of loanwords are on-line adaptations, i.e. foreign words that are borrowed 'here-and-now' (see, for instance, Shinohara 1997, 2000 and Kenstowicz \& Sohn 2001). In this paper, I tentatively treat integrated loanwords and on-line adaptations on a par, assuming that the former reflect on-line adaptations by those speakers who once introduced these words. ${ }^{1}$

\section{Loanword adaptations versus native phonology}

Loanword adaptations are typically transformations that, although absent from the native phonology, do not conflict with it. Counterexamples, however, do exist. In the cases discussed here, the context for the transformations is also present in native underlying forms, but native and foreign forms are not treated alike. Below, I distinguish two types, one in which native and foreign forms undergo different transformations, and one in which native underlying forms - as opposed to loanwords - do not undergo any modification at all.

\subsection{Conflicts between native alternations and loanword adaptations}

Three examples can illustrate the existence of loanword adaptations that are in conflict with some native phonological alternations.

First, consider the following data from Lama, as discussed by Ulrich (1997). In this language, the palatal nasal consonant [n] is allowed in onsets only (1a). In syllable codas, underlying $/ \mathrm{n} /$ undergoes fronting. The context for fronting is created by a general process of word-final schwa deletion after sonorant consonants, accompanied by compensatory lengthening; this is exemplified in (1b). Fronting is shown in (1c), where the sonorant preceding final schwa is $/ \mathrm{n} /$.
a. $/$ nər $/$ [n’̀ $]$

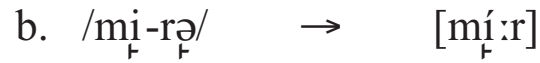
'they'
c. /ti-ņ̃ $\rightarrow$ [tî:n]
'nose'
'elephants'

\footnotetext{
${ }^{1}$ One caveat is in order, though. Since the introduction of the loans, both the source and the borrowing language might have undergone changes. Hualde (2000) nicely illustrates this point.
} 
In loanwords, however, forms with [n] in a syllable coda undergo vowel epenthesis rather than fronting of the nasal (2).
a. [finə]
$<$ Fr. vigne
[vin]
'vineyard'
b. [esappają
Fr. Espagne
[espan]
'Spain'

Next, consider Korean. In this language, [s] is not allowed in syllable codas. In the native phonology, an underlying $/ \mathrm{s} /$ is realized as [t] when it occurs in coda position (3), but in loanwords from English, words with [s] in coda position systematically undergo epenthesis (3b) (Kenstowicz \& Sohn 2001).
a. /nas/ [nat] 'sickle-NOM'
/nas $+\mathrm{i} 1 / \quad$ [nasil $] \quad$ 'sickle-ACC'
b. [posi] < 'boss'
[kirasi] $<$ 'glass'
[mausi] < 'mouse'
[ $\mathrm{k}^{\mathrm{h}}$ arisima $]<$ 'charisma'

The third example is provided by Fula. In this language, neither onset nor coda clusters are allowed. In loanwords from French, an epenthetic vowel is added after the second consonant in liquid+obstruent clusters (4a), but between the consonants of obstruent+liquid clusters (4b) (Paradis and LaCharité 1997).
a. $[$ karda $]<$
Fr. carde [kard]
[forso] $<$
Fr. force [fors]
'card (comb)'
b. $\begin{array}{r}\text { ta:bal }]< \\ {[\text { kala:s }]<}\end{array}$
Fr. table [tabl]
'force'
'table'
Fr. classe [klas]
'flag'

In the native phonology, however, the epenthetic vowel is always inserted after the second consonant, both in the case of liquid+obstruent clusters (5a) and in the (much rarer) case of obstruent+liquid clusters (5b) (data from Paradis 1992).
a. $/$ talk $+\mathrm{ru} / \quad \rightarrow \quad$ [talkuru]
b. $/$ sokl+ka/ $\rightarrow$ [soklaka]
'amulet'
'need'

Within a phonological analysis of the different strategies in native and foreign words in Lama, Korean, and Fula, foreign words should be tagged as such in the lexicon, thus allowing the introduction of rules or constraints that refer to loanwords only. This, then, goes counter to the insight that loanword adaptations either fall out directly of the native phonological grammar or show aspects of this grammar that remain hidden in the absence of loanwords. 


\section{Sharon Peperkamp}

\section{2. 'Unnecessary' adaptations}

Loanword adaptations are mainly transformations that apply to foreign forms that would be ill-formed if they were borrowed without modification. There are, however, several cases of loanword adaptations that appear to be unnecessary, in the sense that they do not repair some ill-formed phonotactic structure.

For instance, in Korean, loanwords from English that end in a voiceless stop are often adapted with an aspirated stop followed by an epenthetic vowel. This occurs especially, though not exclusively, when the preceding vowel is tense (Kang 2003).
a. $\quad\left[\right.$ pæt $\left.^{\mathrm{h}} \mathrm{i}\right]<$ 'bat'
b. $\left[\mathrm{tzk}^{\mathrm{h}} \mathbf{\mathrm { i }}\right]<$ 'deck'
c. $\left[\right.$ hip $\left.^{\mathrm{h}} \mathbf{\mathrm { i }}\right]<$ 'hip'

As noted by Kang, these transformations are unexpected, since native words can end in a voiceless stop (7):
a. [pat]
'field'
b. $[\mathrm{k} æ \mathrm{k}]$
'guest'
c. $[\mathrm{t}$ jip]
'house'

Likewise, in Japanese, on-line adaptations of French words ending in [n] show gemination of the nasal consonant and the appearance of an epenthetic vowel (Shinohara 1997).
a. [duan:ux] $<$ Fr. douane
[dwan]
'customs'
b. [pisin:u] < Fr. piscine [pisin]
'swimming pool'
c. $\quad$ purrocen:ul] $<$
Fr. prochaine [profen]
'next-FEM'

Again, these transformations are unexpected, since native words can end in a moraic nasal consonant, as shown in (9).
a. [teN]
'point'
b. [hoN]
'book'
c. [nip:oN]
'Japan'

Moreover, loanwords from English conform to this native pattern and are adapted with a final moraic nasal.
a. [sukuriiN] < 'screen'
b. [napukiN] $<$ 'napkin'
c. $[$ kotoN $]<$ 'cotton' 


\section{A Psycholinguistic Theory of Loanword Adaptations}

Recently, some other cases of 'unnecessary' adaptations have been studied that might be called generalizations, since they apply to foreign forms that are well-formed in the borrowing language but do not conform to some default pattern. Examples are regularizations of pitch accent patterns in loanwords in Japanese (Shinohara 2000) and Korean (Kenstowicz \& Sohn 2001). It is argued that these languages, which have lexical pitch accent systems, contain default accentuations that emerge in loanword adaptations. The cases concerning vowel epenthesis discussed above, by contrast, cannot be considered generalizations to some default pattern. On the contrary: Korean has no native nouns at all that end in [i] (Yoonjung Kang, personal communication), and Japanese words ending in [n(:)u] are very rare, whereas words ending in a moraic nasal are extremely common (Kimihiro Nakamura, personal communication).

Hence, as before, a phonological account would require a special loanword module in order to accommodate the loanword adaptations in Korean and Japanese. $^{2}$ For the Japanese case, it should even be specified that this module applies to loanwords from French but not to those from English.

\section{Phonetic and perceptual minimality in loanword adaptations}

The cases discussed above all show that loanword adaptations are not necessarily in accordance with the native phonology. It should be noted that introducing one or more special loanword modules is not a viable solution for dealing with these problematic cases. Indeed, loanword adaptations do not involve synchronic alternations, but rather consist of transformations that are applied only during the introduction of the loanword. Once they have made their way into the borrowing language, there is no reason to keep the corresponding forms in the source language as the underlying forms in the lexicon of the borrowing language. It therefore makes no sense to postulate rules or constraints that apply to loanwords only. Alternatively, a solution might be sought in the intuition that loanword adaptations are minimal from a phonetic and/or a perceptual point of view and thus differ from native phonological alternations. Several researchers have indeed argued that either phonetic distance, speech perception, or both play a role in certain loanword adaptations.

Let us first consider the role of phonetics. Loanword adaptations are generally interpreted as being phonologically minimal transformations that yield a legal surface form in the borrowing language. Most often, more than one such transformation is available for a given source word. For several of these cases, it has been argued that phonetic distance might play a role. In particular, the chosen transformation would be the one that is phonetically minimal. Examples include the choice between deletion and epenthesis in languages with a simple syllable structure (Silverman 1992), the absence versus presence of epenthesis (Kang 2003), the quality of epenthetic vowels (Shinohara 1997; Kenstowicz 2001), and

\footnotetext{
${ }^{2}$ Kang (2003) proposes a phonological analysis of the Korean data without such a special loanword module. I will return to this analysis and the problems it raises in section 3 .
} 
the choice between two or more segmental adaptations to repair ill-formed segments (Silverman 1992).

Concerning the role of perception, it has long been known that the way in which we perceive speech depends upon phonological properties of our native language (see, for instance, Polivanov 1931). Accordingly, it has been argued that certain loanword adaptations take place during perception, due to the difficulties that listeners have in perceiving non-native sound patterns (Silverman 1992; Yip 1993; Rose 1999; Gbéto 2000; Kenstowicz 2001; Broselow, in press). According to these authors, adaptations that take place during perception precede the remaining adaptations, and are either pre-grammatical (for instance, Yip 1993) or part of a perception grammar (for instance, Kenstowicz 2001). A slightly different stance is taken by Kang (2003), who distinguishes only a single grammar. This grammar, which is responsible for all loanword adaptations as well as all native alternations, crucially contains correspondence constraints that demand perceptual similarity between input and output forms, as proposed by Steriade (2001).

Various authors have made a connection between speech perception and the role of phonetics (Silverman 1992; Takagi and Mann 1994; Rose 1999; Kenstowicz 2001; Kim and Curtis 2002; Kang 2003). Specifically, defining phonetic distance as auditory distance, they propose that adaptations for which perception plays a role depend upon phonetic minimality. Might it be the case, then, that there are two types of loanword adaptations, those that apply during perception and that are phonetic in nature and those that apply during production and that are phonological in nature? Among the proponents of a two-stage model, only Rose (1999) adheres explicitly to this view. He points out that arguments from perception provide an a priori means to distinguish between phonetic and phonological adaptations. Rose would be right if there were independent evidence as to which part of the adaptations takes place in perception and which part applies in production. However, neither he nor any of the other authors who view a role for perception provides such evidence, and so far, no serious attempt has been made in the loanword literature to interpret psycholinguistic models of speech perception. Rather, it appears that arguments in favor of perceptual transformations are sought for adaptations such as those in section 1, which cannot be accommodated within the native (production) grammar. The distinction between perception and production in loanword adaptations is, therefore, ad hoc.

\section{Loanword adaptations as perceptual assimilations}

Peperkamp \& Dupoux (2003) review psycholinguistic evidence that all aspects of non-native phonological structure, including segments, suprasegments, and syllable phonotactics, are systematically distorted during speech perception. That is, non-native sound structures are assimilated to ones that are well-formed in the native language, both by monolinguals and by bilinguals. Comparing loanword adaptations to experimental speech perception data, they point to a number of striking correspondences. For instance, Korean listeners find it hard to distinguish between the English consonants $[x]$ and $[1]$ in CV-stimuli (Ingram \& See-Gyoon 


\section{A Psycholinguistic Theory of Loanword Adaptations}

1998), and in loanwords from English, word-initial [1] is adapted as [r] (Kenstowicz \& Sohn 2001). In a similar vein, French listeners have severe difficulties perceiving stress contrasts (Dupoux et al. 1997) and in loanwords, stress is systematically word-final, regardless of the position of stress in the source word. Finally, Japanese listeners perceive an illusory vowel within consonant clusters (Dupoux et al. 1999), and in loanwords, such clusters are broken up by vowel epenthesis (Lovins 1975). The latter case is especially revealing, for the following reason. As far as I am aware, within grammatical analyses of loanword adaptations it has never been proposed that the appearance of an epenthetic vowel is due to perception, despite the arguments that the choice of the epenthetic vowel is determined by phonetic minimality. Given that the cases of epenthesis studied in the loanword literature can be derived within the phonology of the borrowing language, perception arguments have simply never been called upon. The robust perception of an illusory vowel by Japanese listeners, however, shows that the presence of vowel epenthesis in Japanese loanwords originates in speech perception. This, then, is evidence that perception can play a role even in adaptations that are in accordance with the native phonological grammar of the borrowing language.

Given the overall similarity between speech perception data and loanword adaptations, Peperkamp \& Dupoux (2003) propose that all loanword adaptations are phonetically minimal transformations that apply in perception. ${ }^{3}$ In psycholinguistic models of perceptual assimilation, non-native segments are assimilated to the closest available phonetic category by a phonetic decoding module that is part of the speech perception system (Best 1994). Peperkamp \& Dupoux (2003) propose that the input to the phonetic decoder is constituted by complete word forms rather than individual segments, thus accounting for perceptual assimilation of non-native suprasegmental and syllabic structures as well. Hence, complete word forms are mapped onto the phonetically closest ones that are well-formed in the native phonology. Cross-linguistic differences in loanword adaptations, then, are predicted to be the result of fine-grained differences in the surface phonetic structure of individual languages. Indeed, language-specific effects in speech perception are entirely due to such differences. For instance, the Japanese subjects in Dupoux et al. (1999) perceive French non-words of the form [VCCV] as [VCuCV], because all other phonotactically legal forms in Japanese, in particular [VCiCV], [VCeCV], [VCoCV], [VCaCV] and [VCV], are phonetically more distant from French [VCCV]. Speakers of other languages with a simple syllable structure might perceive French consonant clusters differently, not because their phonetic decoder uses a different algorithm to compute the closest legal form, but because the forms that are legal in their language are not located at the same place within the (universal) acoustic space as the corresponding Japanese forms.

\footnotetext{
${ }^{3}$ An exception is made for those adaptations that represent a regularization to some default pattern (see Shinohara 2000; Kenstowicz \& Sohn 2001).
} 
Importantly, the hypothesis that all loanword adaptations directly reflect perceptual assimilations accommodates the otherwise problematic data introduced in section 1. First, it naturally accounts for the existence of adaptations that conflict with some native phonological alternation, since loanword adaptations and native alternations are computed by distinct systems. In particular, whereas loanword adaptations represent phonetically minimal transformations, native phonological alternations are not necessarily minimal from a phonetic point of view. Second, it provides an explanation for the presence of 'unnecessary' adaptations, which do not repair some ill-formed phonotactic structure. That is, a phonological surface form in a given source language that has a faithful surface correspondent in a borrowing language can be phonetically closer to a different surface form in the borrowing language, depending upon phonetic details in the realization of the surface forms in both the source and the borrowing language. For instance, in her careful phonetic study, Kang (2003) shows that this is the case for the Korean adaptation of word-final stops in loanwords from English, as illustrated in (6) above. Word-finally, Korean allows for voiceless stops, but they are strictly unreleased. English word-final stops that tend to be released, such as those that are preceded by a tense vowel, are therefore most often adapted as a sequence of stop plus vowel.

Of course, much more research is needed to empirically test the correspondence between loanword adaptations and perceptual assimilations. So far, not many speech perception experiments that specifically aim at comparing loanword data to the perception of non-native sound patterns have been carried out, but some encouraging results are already available (Takagi \& Mann 1994; Vendelin \& Peperkamp, in press). For instance, Vendelin \& Peperkamp (in press) study the asymmetry between French and English loanwords in Japanese, where the former but not the latter have a phonotactically unnecessary epenthetic vowel if the source word ends in [n] (see (8) and (10) above). They show that this asymmetry mirrors the way in which Japanese speakers perceive French and English stimuli ending in $[\mathrm{n}]$. That is, in a speech perception experiment with non-words produced by French and American English speakers and a forced choice identification task, Japanese subjects perceived an epenthetic vowel in $96 \%$ of the French stimuli and in only 59\% of the English stimuli. Moreover, the perception of an epenthetic vowel is shown to depend upon the length of the nasal consonant and the presence of a release with vocalic formants (rather than an aspirated release or no release at all); specifically, the percentage of responses with epenthesis positively correlated with the duration of the nasal consonant - including its release - multiplied by its intensity.

Finally, what are the consequences of the hypothesis that loanword adaptations reflect perceptual assimilations for a formal grammatical analysis of these adaptations? Recently, it was argued that the phonological grammar contains correspondence constraints that demand perceptual similarity between input and output forms (Steriade 2001). We have seen that Kang (2003) accordingly proposes to account for loanword adaptations within the native phonological 


\section{A Psycholinguistic Theory of Loanword Adaptations}

grammar that is thus enriched with these constraints. Note, however, that the problem of conflicts between native alternations and loanword adaptations remains. For instance, recall the Korean data in (3) above, showing that loanwords with a coda [s] undergo vowel epenthesis, while coda $/ \mathrm{s} /$ in native underlying forms turns into [t]. Clearly, perceptual minimality is achieved in either the native alternation or the loanword adaptation, but not both. Given the fact that word-final stops are strictly unreleased in Korean, it seems likely that it is the loanword adaptation, and not the native alternation, that constitutes a perceptually minimal change; that is, [s] is probably closer to [si] than it is to [t?] from a perceptual point of view. Similarly, we have seen that Lama and Fula apply different transformations to coda [n] and consonant clusters, respectively, when they occur in a native underlying form and in a foreign form. Hence, even a grammar that contains correspondence constraints demanding perceptual similarity cannot uniformly account for the derivation of both native words and loanwords. In other words, attempts to deal with native alternations and loanword adaptations within a single phonological grammar appear to be in vain. This of course leaves open the possibility to model loanword adaptations in a separate perception grammar that makes reference to fine-phonetic detail. Whether such a grammar fares better than psycholinguistic accounts of perceptual assimilation is an open question.

\section{Conclusion}

Most loanword adaptations seemingly change the shape of foreign words in order to make them comply with the surface phonological structure of the borrowing language. Within output-oriented phonological theories, the same pressure is held responsible for the transformations of underlying forms during the mapping onto surface forms in the native phonology. Given that there are not that many ways to transform an illegal form into a legal one in an economical way, loanword adaptations thus exhibit a global resemblance to native alternations. Upon closer inspection, however, the correspondence between the two phenomena simply does not hold, as shown by the examples in section 1. Fortunately, there is a third phenomenon that is driven by the requirement to respect native phonological structure: during speech perception, the process of phonetic decoding maps nonnative forms onto forms that are in accordance with the native phonology. This process is thus influenced by but not identical to the phonology of the listener's native language. The perceptual assimilations that result from it are completely automatic and apply beyond the listener's awareness. Moreover, they are based upon phonetic rather than phonological distance, and in the cases studied so far they correspond to the transformations that take place in loanword adaptations.

The hypothesis that loanword adaptations are not part of the phonological grammar but reflect the psycholinguistic process of phonetic decoding is a strong one that might be overly simplistic. Other factors, yet to be determined, can equally be at stake. For instance, orthography can be expected to play a role in adaptations that are either based on written input or established by speakers who 


\section{Sharon Peperkamp}

know the spelling of the loanwords in the source language. Given the metalinguistic character of orthography, adaptations that are (partly) based on spelling correspondences are of course of little interest to linguistic analyses. Whereas in the case of integrated loanwords the influence of orthography is not always easy to establish, in on-line adaptations that are gathered experimentally, orthography is a factor that can be controlled for. In particular, contemporary loanword data can be collected by presenting oral renderings of non-words in the source language to speakers of the borrowing language and ask them how they would introduce these forms into their own language. Likewise, in the case of massive borrowing from a single source language, there might be some standardization of adaptations that initially show a certain amount of variability. This variability, which can also be studied with on-line adaptations, is predicted to depend upon the phonetic proximity of competing well-formed structures in the borrowing language. For instance, a non-native sound that is almost equidistant to two different native sounds is likely to show more variability in its adaptation than one that is phonetically much closer to one of the native sounds than to all others. Note that there is an obvious parallel in speech perception experiments, where certain perceptual assimilation effects show more intra- and inter-subject variability than others.

To conclude, adaptations that are in conflict with some native alternation of the borrowing language and phonotactically 'unnecessary' adaptations are highly problematic for analyses of loanwords that derive the adaptations within the phonological grammar of the borrowing language. In contrast, their presence is expected under the hypothesis that loanword adaptations are basically phonetic rather than phonological in nature, and originate in the process of phonetic decoding during speech perception. This hypothesis is motivated independently by experimental data on the perception of non-native sound structures. Studying loanword adaptations within a psycholinguistic framework of speech perception therefore appears a promising avenue.

\section{Acknowledgments}

For comments and discussion, I would like to thank Nick Clements, Abigail Cohn, Emmanuel Dupoux, Yoonjung Kang, Michael Kenstowicz, and participants at the $30^{\text {th }}$ Berkeley Linguistics Society meeting. Financial support from the CNRS ('Cognition et Traitement de l'Information') is gratefully acknowledged.

\section{References}

Best, C. 1994. The emergence of native-language phonological influences in infants: A perceptual assimilation model. In J. Goodman \& H. Nusbaum (eds.) The Development of Speech Perception: The Transition from Speech Sounds to Spoken Words, 167-224. Cambridge, MA: MIT Press. 
Broselow, E. 2000. Stress, epenthesis, and segment transformation in Selayarese loans. In S. Chang, L. Liaw \& J. Ruppenhofer (eds.) Proceedings of the Twenty-fifth Annual Meeting of the Berkeley Linguistics Society, 311-325. Berkeley, CA: Berkeley Linguistics Society.

Broselow, E. In press. Language contact phonology: Richness of the stimulus, poverty of the base. Proceedings of NELS 34. Amherst, MA: GLSA.

Dupoux, E., K. Kakehi, Y. Hirose, C. Pallier \& J. Mehler. 1999. Epenthetic vowels in Japanese: A perceptual illusion? Journal of Experimental Psychology: Human Perception and Performance 25: 1568-1578.

Dupoux, E., C. Pallier, N. Sebastián-Gallés \& J. Mehler. 1997. A destressing "deafness" in French? Journal of Memory and Language 36: 406-421.

Gbéto, F. 2000. Les emprunts linguistiques d'origine européenne en Fon. Köln: Rüdiger Köppe Verlag.

Golston, C. \& P. Yang. 2001. White Hmong loanword phonology. In C. Féry, A. Green \& R. van de Vijver (eds.) Proceedings of HILP 5, 40-57. Potsdam: University of Potsdam.

Hualde, J. 2000. Patterns of correspondence in the adaptation of Spanish borrowings in Basque. In S. Chang, L. Liaw \& J. Ruppenhofer (eds.) Proceedings of the Twenty-fifth Annual Meeting of the Berkeley Linguistics Society, 348-358. Berkeley, CA: Berkeley Linguistics Society.

Hyman, L. 1970. The role of borrowings in the justification of phonological grammars. Studies in African linguistics 1: 1-48.

Ingram, J. \& P. See-Gyoon. 1998. Language, context, and speaker effects in the identification and discrimination of English / $\mathrm{r} /$ and /1/ by Japanese and Korean listeners. Journal of the Acoustical Society of America 103: 1161-1174.

Jacobs, H. \& C. Gussenhoven. 2000. Loan phonology: perception, salience, the lexicon and OT. In J. Dekkers, F. van der Leeuw \& J. van de Weijer (eds.) Optimality Theory: Phonology, Syntax, and Acquisition, 193-210. Oxford: Oxford University Press.

Kang, Y. 2003. Perceptual similarity in loanword adaptation: Adaptation of English post-vocalic word-final stops to Korean. Phonology 20: 219-273.

Kenstowicz, M. 2001. The role of perception in loanword phonology. Linguistique Africaine 20.

Kenstowicz, M. \& H.-S. Sohn. 2001. Accentual adaptation in North Kyungsang Korean. In M. Kenstowicz (ed.) Ken Hale. A Life in Language, 239-270. Cambridge, MA: MIT Press.

Kim, S. \& E. Curtis. 2002. Phonetic duration of English /s/ and its borrowing in Korean. In N. Akatsuka, S. Strauss \& B. Comrie (eds.) Japanese/Korean Linguistics 10. Stanford: CSLI.

Lovins, J. 1975. Loan Words and the Phonological Structure of Japanese. Bloomington: Indiana University Linguistics Club.

Paradis, C. 1992. Lexical Phonology and Morphology: The Nominal Classes in Fula. New York: Garland. 


\section{Sharon Peperkamp}

Paradis, C. 1995. Native and loanword phonology as one: constraints versus rules. In K. Elenius \& P. Branderud (eds.) Proceedings of the 13th International Congress of Phonetic Sciences 3, 74-81. Stockholm.

Paradis, C. \& D. LaCharité. 1997. Preservation and minimality in loanword adaptation. Journal of Linguistics 33: 379-430.

Peperkamp, S. \& E. Dupoux. 2003. Reinterpreting loanword adaptations: The role of perception. Proceedings of the 15th International Congress of Phonetic Sciences, 367-370. Barcelona: Causal Productions.

Polivanov, E.i.D. 1931. La perception des sons d'une langue étrangère. Travaux du Cercle Linguistique de Prague 4: 79-96.

Rose, Y. 1999. A structural account of root node deletion in loanword phonology. Canadian Journal of Linguistics 44: 359-404.

Shinohara, S. 1997. Analyse phonologique de l'adaptation japonaise de mots étrangers. Doctoral dissertation, Université de Paris III.

Shinohara, S. 2000. Default accentuation and foot structure in Japanese: evidence from Japanese adaptations of French words. Journal of East Asian Linguistics 9: 55-96.

Silverman, D. 1992. Multiple scansions in loanword phonology: Evidence from Cantonese. Phonology 9: 289-328.

Steriade, D. 2001. The phonology of perceptibility effects: The P-map and its consequences for constraint organization. Ms., UCLA.

Takagi, N. \& V. Mann. 1994. A perceptual basis for the systematic phonological correspondences between Japanese loan words and their English source words. Journal of Phonetics 22: 343-356.

Ulrich, C. 1997. Loanword adaptation in Lama: Testing the TCRS model. Canadian Journal of Linguistics 42: 415-463.

Vendelin, I. and S. Peperkamp. In press. Evidence for phonetic adaptation of loanwords: An experimental study. Proceedings of Journées d'Etudes Linguistiques de l'Université de Nantes.

Yip, M. 1993. Cantonese loanword phonology and Optimality Theory. Journal of East Asian Linguistics 2: 261-291.

Sharon Peperkamp

Laboratoire de Sciences Cognitives et Psycholinguistique

46, Rue d'Ulm

75005 Paris

France

Sharon.Peperkamp@ens.fr 